\title{
MONITORING AND INVESTIGATING SPACE WEATHER EFFECTS WITH MERIDIONAL CHAIN OF INSTRUMENTS IN YAKUTIA: A BRIEF OVERVIEW
}

\author{
D.G. Baishev \\ Yu.G. Shafer Institute of Cosmophysical Research \\ and Aeronomy SB RAS, \\ Yakutsk, Russia,baishev@ikfia.ysn.ru
}

\section{S.N. Samsonov}

Yu.G. Shafer Institute of Cosmophysical Research and Aeronomy SB RAS,

Yakutsk, Russia

\section{A.V. Moiseev}

Yu.G. Shafer Institute of Cosmophysical Research and Aeronomy SB RAS,

Yakutsk, Russia

\section{R.N. Boroyev}

Yu.G. Shafer Institute of Cosmophysical Research and Aeronomy SB RAS,

Yakutsk, Russia

\section{A.E. Stepanov}

Yu.G. Shafer Institute of Cosmophysical Research and Aeronomy SB RAS,

Yakutsk, Russia

\author{
V.I. Kozlov \\ Yu.G. Shafer Institute of Cosmophysical Research \\ and Aeronomy SB RAS, \\ Yakutsk, Russia
}

\author{
A.A. Korsakov \\ Yu.G. Shafer Institute of Cosmophysical Research \\ and Aeronomy SB RAS, \\ Yakutsk, Russia
A.A. Toropov
Yu.G. Shafer Institute of Cosmophysical Research and Aeronomy SB RAS,
Yakutsk, Russia \\ A. Yoshikawa \\ International Center for Space Weather Science \\ and Education, Kyushu University, \\ Fukuoka, Japan

\section{K. Yumoto} \\ International Center for Space Weather Science \\ and Education, Kyushu University, \\ Fukuoka, Japan
}

\begin{abstract}
The Yakutsk Meridional Chain (YMC) of IKFIA SB RAS, located along the $190^{\circ}$ magnetic meridian, is equipped with geophysical and radiophysical instruments for monitoring space weather in northeastern Russia. YMC includes four basic stations in Yakutsk, Tixie, Zhigansk, and Maymaga, and six additional observation sites in Neryungri, Zyryanka, Kystatyam, Dzhardzhan, Chokurdakh, and Kotelny Island. It provides continuous monitoring of near-Earth space in order to obtain data on magnetic field variations, cosmic radio noise, VLF radiation, and ionospheric parameters in the complex upper atmosphere - ionosphere -
\end{abstract}

magnetosphere system. In addition, long-term experimental research into space weather effects on human health is conducted at Tixie and Yakutsk. The report describes the meridional chain of instruments at subauroral and auroral latitudes and gives a brief overview of scientific results of monitoring and investigation into space weather effects in Yakutia. It also observes participation of IKFIA SB RAS in international projects (Intermagnet, MAGDAS, GIRO).

Keywords: meridional chain, magnetometer, digisonde, space weather.

\section{INTRODUCTION}

The widely used term "space weather" introduced in recent years denotes environmental conditions in nearEarth space. Space weather is the main object of aeronomy research conducted by IKFIA SB RAS. Environmental conditions comprise interrelated physical processes in different regions of near-Earth space, which are driven by solar activity.

There are diverse manifestations of these processes in the upper atmosphere and near-Earth space. The study of regularities of space weather formation relies on the fact that space weather affects meteorological processes in the lower and middle atmosphere, the reliability of operation of different technical systems in space and on Earth, and human health.

Many countries have now enacted a national program to study space weather effects. A number of international programs are aimed at in-depth studies of con- ditions in near-Earth space and their impact on the human environment, as well as at the study of global climatic changes on Earth - International Living with a Star (ILWS) Program, Climate and Weather of the SunEarth System (CAWSES), International Space Weather Initiatives (ISWI), and others.

In this paper, we present a review of the space weather research and results obtained at IKFIA SB RAS in Russia. The Yakutsk Meridional Chain (YMC) and the main instrumentation are described in Section "Methods and Instrumentation". New results of optical, ionospheric, VLF emissions, atmospheric electricity, cosmic noise absorption, and multi-instrumental observations in Yakutia are given in Section "Results from the Yakutsk Meridional Chain". Participation of IKFIA SB RAS in international projects through the application of available multi-instrumental base is described in Section "International Cooperation". 


\section{METHODS}

\section{AND INSTRUMENTATION}

Space weather manifests itself in many different ways such as changes in the complex and dynamic magnetosphere-ionosphere system, generation of geomagnetic pulsations in a wide frequency range, precipitation of energetic particles, influences on pipelines and human health during geomagnetic storms and magnetospheric substorms.

IKFIA SB RAS carry out experimental studies of processes in near-Earth space and in the upper atmosphere, using magnetic, optical, and radiophysical measurements.

The main tasks of aeronomy research are:

- a comprehensive study of wave activity during periods of magnetospheric disturbances based on global geomagnetic observations, optical and radiophysical measurements made at YMC (see Figure 1);

- a study of thermal regime, large-scale circulation, and wave disturbances in the high-latitude thermosphere and mesosphere;

- a study of atmospheric electrodynamic processes, their relationship to solar activity, ionospheric and magnetospheric processes.

The Yakutsk meridional chain of geophysical and radiophysical stations of IKFIA SB RAS (Figure 1), which are located along the $190^{\circ}$ magnetic meridian, is the most appropriate for the study of magnetosphereionosphere interactions in the vicinity of the plasma sheet of the magnetosphere, the boundary of the ring current, and the plasmapause. YMC is placed in the northeastern region of Russia with a large difference between geographic and geomagnetic coordinates, where longitudinal effects in spatial distribution of geophysical parameters are most pronounced [Mamrukov, Filippov, 1988; Solovyev et al., 2002].

The main instrumentation for monitoring and investigating space weather effects in Yakutia are described on the IKFIA website in Section "Experimental base" (http://ikfia.ysn.ru/en/experimental-base.html).

Absolute magnetic data from the Yakutsk observatory allow us to study both fast changes (geomagnetic pulsations, substorms, magnetic storms) and slow, socalled secular changes of the geomagnetic field with a period over 1 year. Digital data (one-minute absolute magnetic field values and $\mathrm{K}$ indices) are available since 2007. During that year, the observatory was equipped with modern instruments in the context of cooperation between IKFIA SB RAS and GeoForschungsZentrum (Potsdam, Germany); the observatory equipment is described in [Moiseev et al., 2011].

The MAGDAS-9 fluxgate magnetometer furnishes measurements of $\mathrm{H}, \mathrm{D}, \mathrm{Z}$ magnetic field components with an accuracy of $0.01 \mathrm{nT}$ in a range of $\pm 70000 \mathrm{nT}$ and a sampling rate up to $10 \mathrm{~Hz}$ [Yumoto et al., 2006]. Digital magnetic data from six stations (Kotelny Island KTN, Tixie - TIX, Chokurdakh - CHD, Zhigansk ZGN, Zyryanka - ZYK, and Yakutsk - YAK) acquired in September 2011 (except for Zyryanka, September 2013) are stored on external hard drive and original 2 GB flash cards with raw magnetic data. They are sent to ICSWSE (Kyushu University, Fukuoka, Japan) once a year.
Two all-sky TV cameras with a temporal resolution of $4 \mathrm{~s}$ were installed in Tixie $\left(71.6^{\circ} \mathrm{N}, 128.9^{\circ} \mathrm{E}\right)$ in 1994 and Zhigansk $\left(66.8^{\circ} \mathrm{N}, 123.4^{\circ} \mathrm{E}\right)$ in 1995 . An allsky TV camera was described in [Shiokawa et al., 1996]. Archive of optical observations until 2013 is stored on $8-\mathrm{mm}$ cassette tapes, and most auroral events are digitized by $240 \times 320$ pixel frames in MOV or AVI video formats.

The Digisonde Portable Sounder (DPS) [Reinisch et al., 1997] produced by the University of Massachusetts Lowell's Center for Atmospheric Research (UMLCAR) (http://ulcar.uml.edu/) consists of the main unit, monitor, two transmitter antennas, four crossed magnetic dipole receiver antennas, GPS receiver, and battery backup power. The main unit includes two computers, a transmitter, four receivers, and a signal processor. The digisonde DPS-4 has a number of distinctive features that make this device unique. Technical features of the digisonde are its low radiation (the power of two transmitters is $150 \mathrm{~W}$ each) and special methods of signal processing (polarization matching, coherent processing, coherent accumulation) [Reinisch et al., 1997]. Ionospheric sounding is conducted by a similar digisonde DPS-4 at Yakutsk and Zhigansk in the range from 1 to $12 \mathrm{MHz}$ for the standard 15-minute program. Digital ionospheric data in SAO formats are stored for Yakutsk from November 2002 to the present day and for Zhigansk from November 2003 to December 2016 on CDROM disks and external hard drive.

We describe the instrumentation for VLF emission and riometer observations in the next sections.

\section{RESULTS FROM THE YAKUTSK MERIDIONAL CHAIN}

\section{Optical observations}

A research team led by Prof. S.I. Solovyev has analyzed spatial-temporal characteristics of geomagnetic pulsations and non-stationary structures of auroral luminosity during magnetic disturbances until 2010 at IKFIA SB RAS. Then these investigations were continued by D.G. Baishev.

Baishev et al. [2012] described some results of statistical studies of large-scale undulations observed for 15 years (1994-2008) at Tixie and Zhigansk. For the first time it was shown that undulations registered in the evening sector (17-23 LT) occurred during magnetic storms (22 events) and in the absence of magnetic storms (32 events).

Figure 2 exemplifies simultaneous observations of large-scale undulations made with the DMSP F15 satellite and all-sky TV camera at Tixie between 09:4809:52 UT on December 25, 2005. Referring to Figure 2, $b$, five diffuse "tongues" or large-scale undulations in the evening sector ( 19-21 MLT) were observed on the equatorward boundary of diffuse aurora. Discrete auroral structures of various shapes and dimensions were registered northward of this boundary. The DMSP F15 satellite flew almost over Tixie at 09:48 UT. In the field of view of the all-sky TV camera at Tixie with a radius of $400 \mathrm{~km}$ (circle in Figure 2, b), we can distinguish three auroral structures: the discrete auroral arc on 


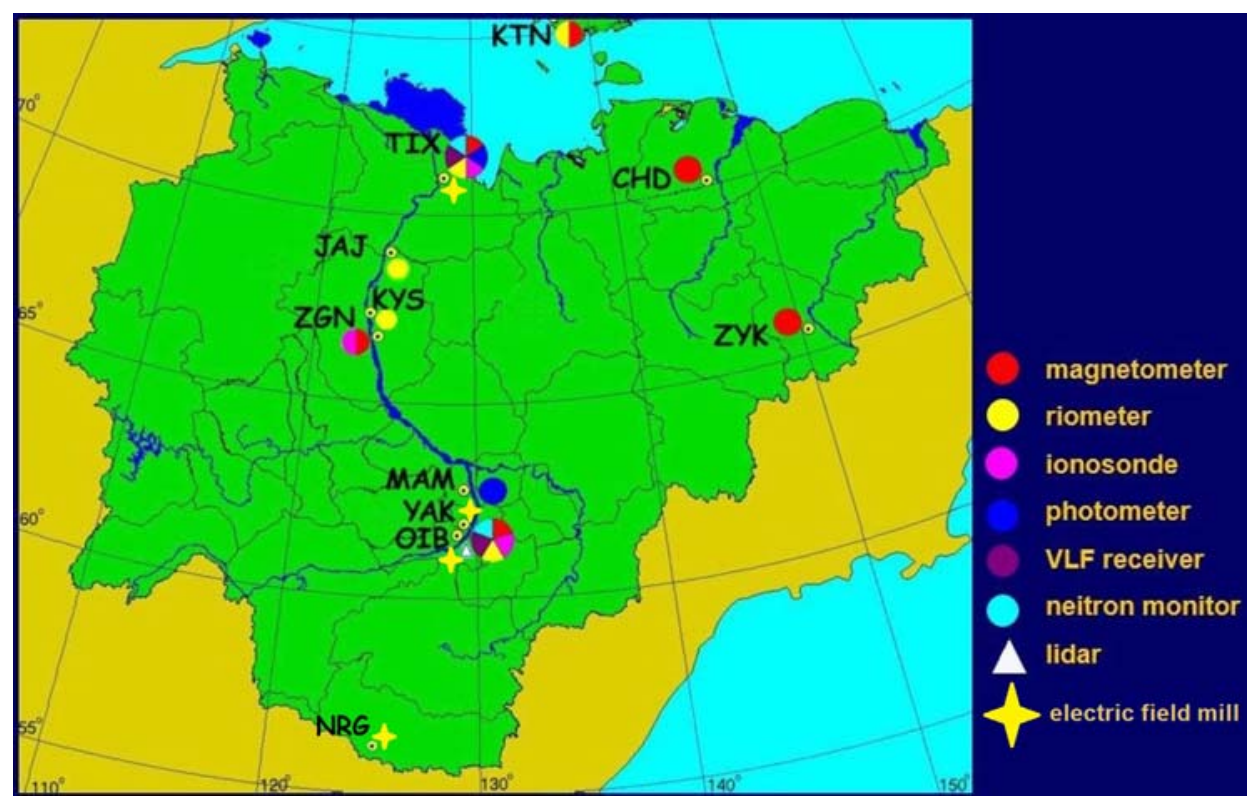

Figure 1. The Yakutsk meridional chain of geophysical stations

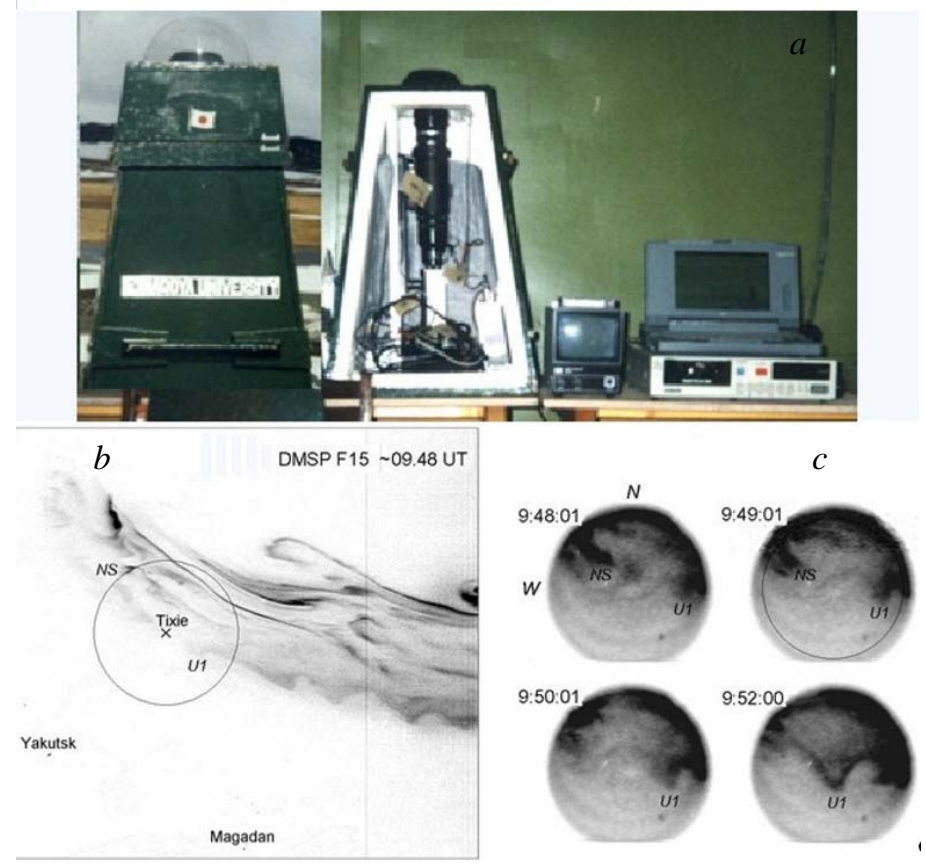

Figure 2. The all-sky TV camera at Tixie (a), simultaneous observations of undulations made with the DMSP F15 satellite (b) and the all-sky TV camera at Tixie (c) on December 25, 2005

the northern horizon, the discrete structure that extends from north to south (NS) and is located at the northwestern edge, and the undulation U1 located to the east of the zenith of Tixie at a distance of $\sim 200 \mathrm{~km}$. The discrete structure NS and the undulation U1 are clearly visible on the TV frames captured at 09:48 and 09:49 UT. The TV frames taken at 09:50 and 09:52 UT are presented to illustrate the motion of the undulation U1 from the eastern edge of TV frame to the zenith of Tixie. The westward velocity of the undulation U1 was $\sim 0.8 \mathrm{~km} / \mathrm{s}$.

Baishev et al. [2014] have performed a statistical study of evening-side undulations during low planetary magnetic activity $\left(K_{\mathrm{p}}<3\right)$, using optical observations at
Tixie over the period 1994-2008. They employed 1-min data from the OMNI database (http://omniweb.gsfc. nasa.gov/) to examine solar wind and geomagnetic activity conditions for 14 undulation events. It was found that the undulations occurred when the interplanetary magnetic field was southward and the solar wind energy flux was high for a long time (up to 4 hours) before an undulation event. A significant smooth growth was registered in values of the $A E$ index and $\mathrm{H}$ component of the magnetic field at Tixie due to the increased solar wind energy transfer into Earth's magnetosphere (see Figure 3). The authors suggested that the generation of evening-side undulations under $K_{\mathrm{p}}<3$ is related to physic- 

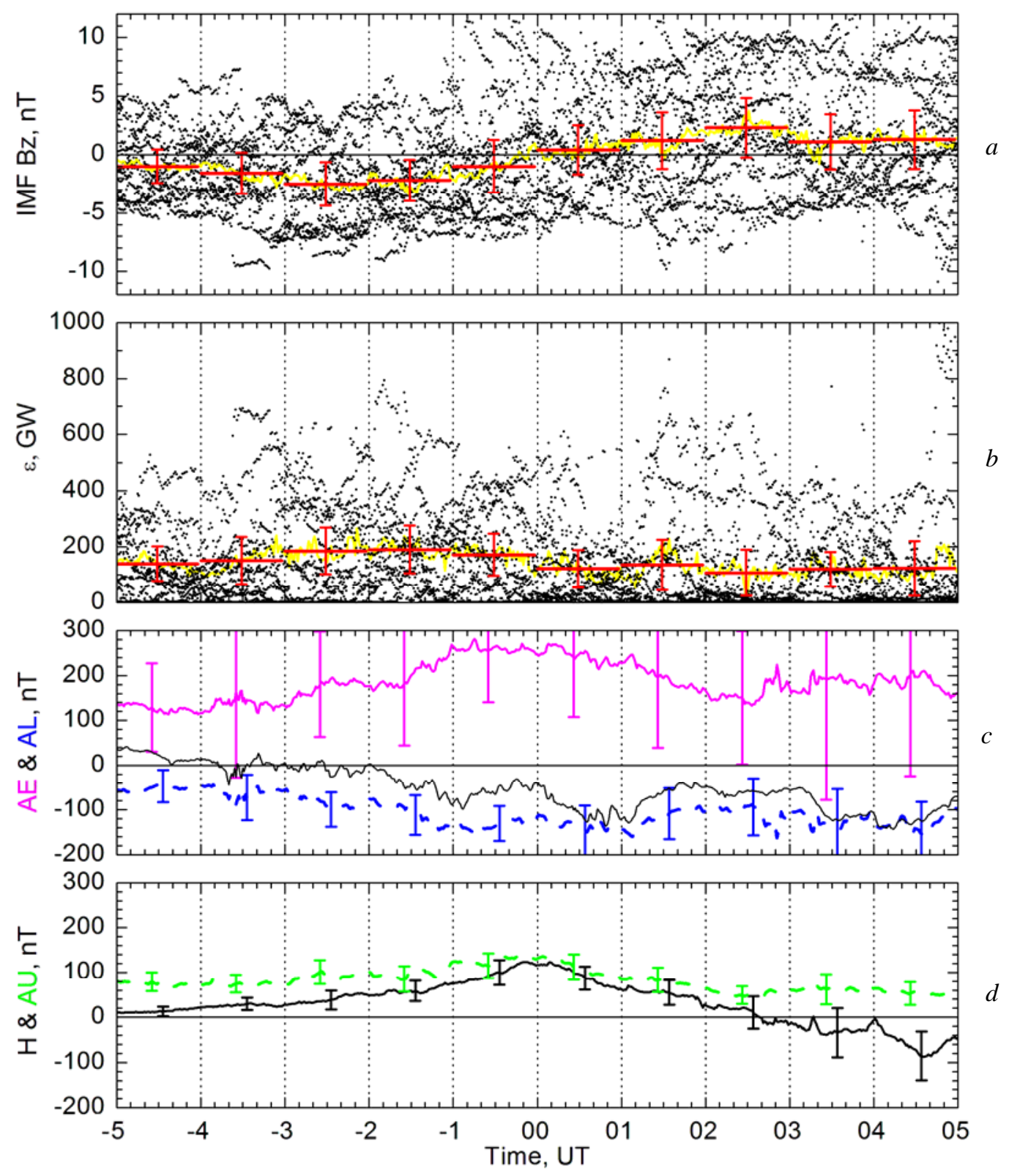

Figure 3. Variations of average values obtained using a superposed epoch technique: IMF Bz component (a), Akasofu's parameter $\varepsilon(b), A E$ index (magenta), $A L$ index (dashed blue) and horizontal component of the magnetic field (thin black) at Barrow (c), horizontal component of the magnetic field (thick black) at Tixie, and $A U$ index (dashed green) (d). The red horizontal lines represent hourly averaged values of IMF $B_{z}$ component and $\varepsilon$. The vertical (red and other colors) lines represent data variations, $\pm 0.5 \sigma$ (standard deviation). The zero epoch is the beginning of undulation registration

cal processes in the inner magnetosphere, which captures mid-latitude variations of plasma drift on the dusk side and is enhanced during subauroral polarization stream events.

\section{Ionospheric observations}

Time synchronization of the digisonde supported by GPS receivers gave the opportunity to start regular synchronous measurements using the oblique sounding method over the Yakutsk-Zhigansk subauroral radio path, the length of which on the Earth surface is $\sim 620 \mathrm{~km}$. Figure 4 presents the example of synchronous observations of additional echoes (1F2 echo at Yakutsk and 1F2 and 1F1 echoes at Zhigansk) made with DPS-4 digisondes over the Yakutsk-Zhigansk path at 07:30 UT on May 14, 2004. On the basis of the parabolic ionospheric model and numerical simulation of propagation over the Yakutsk-Zhigansk radio path, it is shown that there is good agreement between echoes of inclined reflections on vertical sounding ionograms and calculated echoes [Stepanov, Filippov, 2014].

Stepanov et al. [2016] have examined ionospheric observations (daily $\mathrm{f}$ plots) at YMC (YakutskZhigansk-Batagai-Tixie Bay) with sharp decreases in the critical frequency of the regular ionospheric F2 layer $\left(f_{\mathrm{o}} \mathrm{F} 2\right)$. They analyzed data for 1968-1983 and presented statistics on $f_{\mathrm{o}} \mathrm{F} 2$ sharp decrease observations, which indicate that these sharp decreases were mainly 

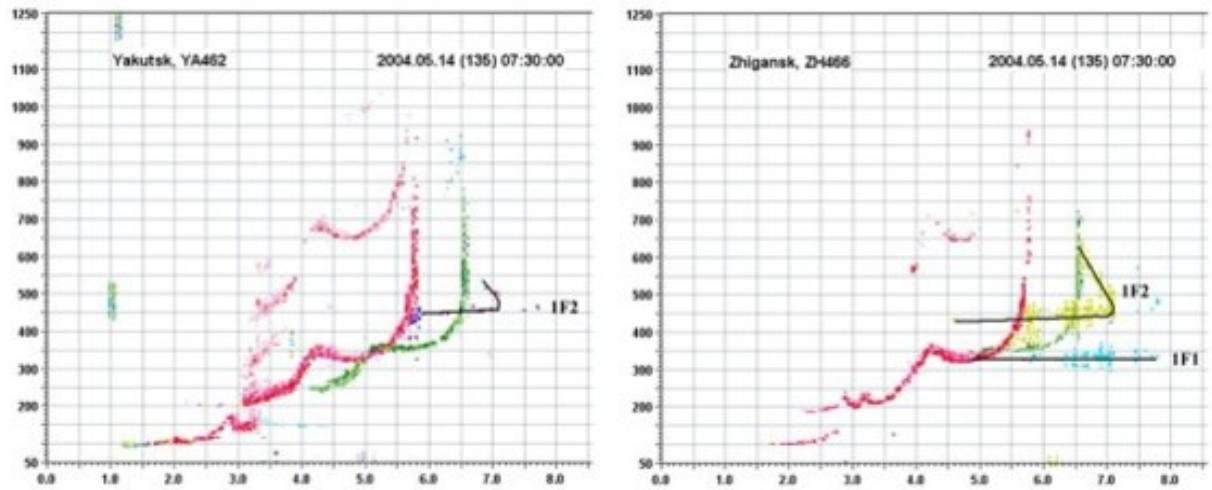

Figure 4. Synchronous observations by DPS-4 digisondes at the Yakutsk and Zhigansk ionospheric stations at 07:30 UT on May 14, 2004

registered in equinoctial months and during afternoon and evening hours under moderately disturbed geomagnetic conditions. Calculations performed using the prognostic model of the high-latitude ionosphere show that the $f_{\mathrm{o}} \mathrm{F} 2$ sharp decrease position coincides with the equatorial boundary of large-scale plasma convection in the dusk MLT sector.

The comparison of the selected cases of polarization jet observation at the ground stations with measurements of energetic ions aboard the AMPTE/CCE satellite suggests that these phenomena occur simultaneously and on the same L shells [Khalipov et al., 2016]. Polarization jet observations aboard DMSP satellites make it possible to statistically determine the dependence of its equatorial boundary position on the $A E$ index value. It is also shown that in the case of isolated magnetic disturbances the position of the inner boundary of energetic ion injection measured aboard the AMPTE/CCE satellite depends on the $A E$ index. It is found that the dependences of both the boundaries on the $A E$ index match over a wide range of $A E$ variations. This indicates that the equatorial boundary of polarization jet band and the inner boundary of energetic ion injection are physically interrelated and are formed on the same L shells during substorms.

\section{VLF emission observations}

The Ionosphere and Magnetosphere Radio Emission Laboratory carries out investigations of very lowfrequency (VLF: 3-30 kHz) emissions of thunderstorm, magnetospheric, and anthropogenic origin.

The intensity of the VLF noise of magnetospheric, ionospheric, and atmospheric origin at 11 fixed frequencies from $470 \mathrm{~Hz}$ to $8.7 \mathrm{kHz}$ has been continuously registered since 1972 at the station located at a distance of $25 \mathrm{~km}$ to the south of Yakutsk which is free from industrial noises. Continuous and long-term recording allows the study of solar activity and space weather effects in variations of the VLF noise intensity over a period of several solar cycles. The relation between long-term variations in the thunderstorm VLF radio noise intensity and solar activity for 1979-2006 has been studied. The sunspot number was used as a parameter characterizing solar activity. The VLF noise intensity registered at
$8.7 \mathrm{kHz}$ at Yakutsk characterizes thunderstorm activity in Eastern Siberia and in the African thunderstorm center. The highest anticorrelation coefficients ( $R=-0.75$ ) between the sunspot number and the thunderstorm discharge intensity were obtained for thunderstorms in Eastern Siberia [Kozlov et al., 2009].

Amplitude and phase variations of VLF signals of the RSDN-20 system have been continuously registered in Yakutsk since 2009. The radio transmitters located near Krasnodar, Novosibirsk, and Khabarovsk sequentially radiate pulses at frequencies of $11.9,12.6$, and $14.9 \mathrm{kHz}$. The VLF radio noise intensity is observed during the period between radio signal pulses at the same frequencies. VLF signals are recorded at Tixie since 2015. Model parameters of VLF phase variations depending on X-ray flux and solar zenith angle over the long propagation path Novosibirsk-Yakutsk are adapted as those during sudden phase anomalies and undisturbed conditions (see Figure 5). For daily propagation path conditions the coincidence of simulated data with satellite data has a satisfactory rating [Korsakov et al., 2014].

\section{Atmospheric electricity observations}

The atmospheric electric field strength with 1-second resolution has been regularly and continuously measured since 2009 in Yakutia. Electrostatic field mills EFM-100, installed at Yakutsk (YAK), Oybenkel (OIB), Neryungri (NRG), and Tixie (TIX), allow us to measure variations of electric field strength under fair-weather, thunderstorm, foggy, and snowstorm conditions.

The EFM-100 is an atmospheric electric field monitor of high quality and low cost, which connects to a personal computer to display and record data. The EFM-100 senses an electric field through the repeated exposure and shielding of a series of sensitive electrodes. The main EFM-100 hardware specifications are as follows: electric field range from -20 to $+20 \mathrm{kV} / \mathrm{m}$, response time of $0.1 \mathrm{~s}$, and digital output resolution of $0.01 \mathrm{kV} / \mathrm{m}$.

It is found that the electric field variation has a trend toward a decrease in the amplitude of seasonal field strength variations for the 2009-2013 period (see Figure 6). A possible cause of the observed trend 


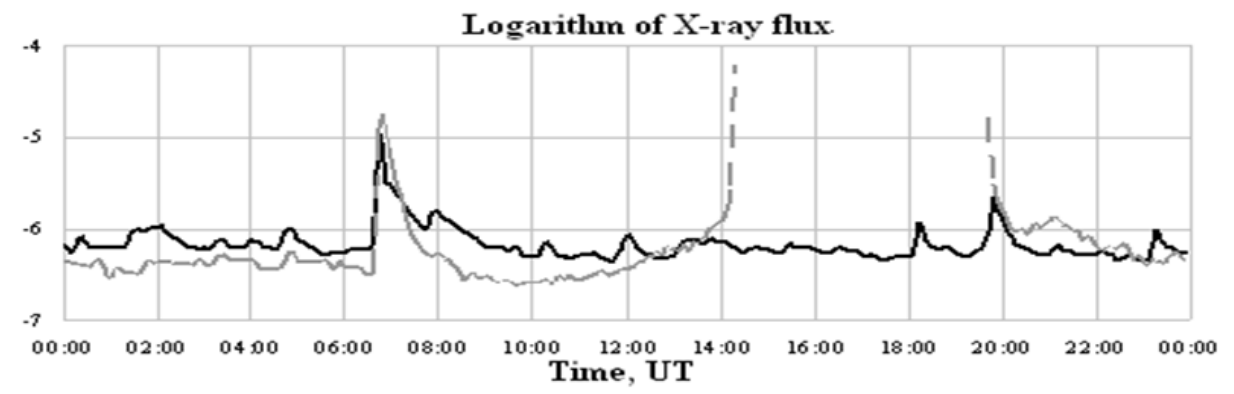

X-ray flux (GOES-15)

- X-ray flux (model)

Signal phase variation Novosibirsk, $14,9 \mathrm{kHz}$

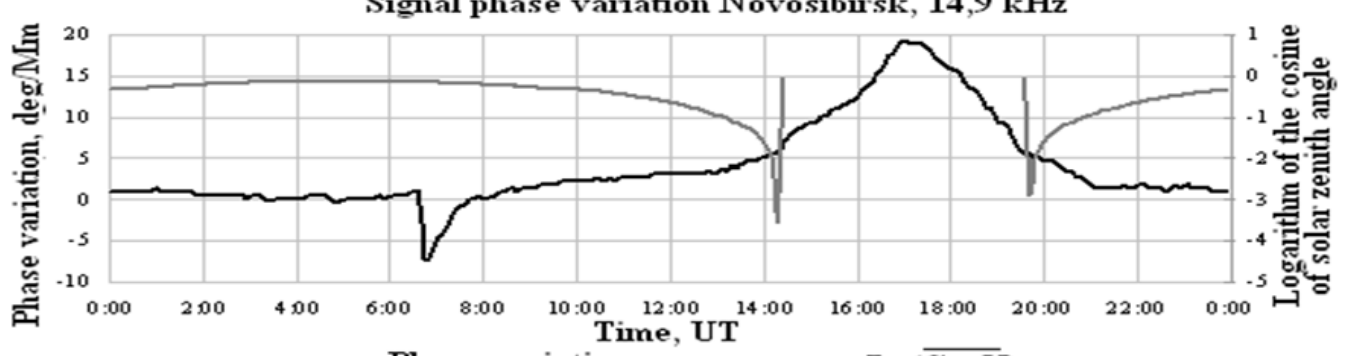

Phase variation

$\operatorname{Lg}(\overline{\operatorname{Cos} X})$

Figure 5. Comparison between data on X-ray flux on June 10, 2012 and values obtained using model calculations from the phase variation of the signal obtained from the transmitter at Novosibirsk (left scale in the bottom panel) and the cosine of solar zenith angle over the Novosibirsk-Yakutsk path (right scale in the bottom panel)
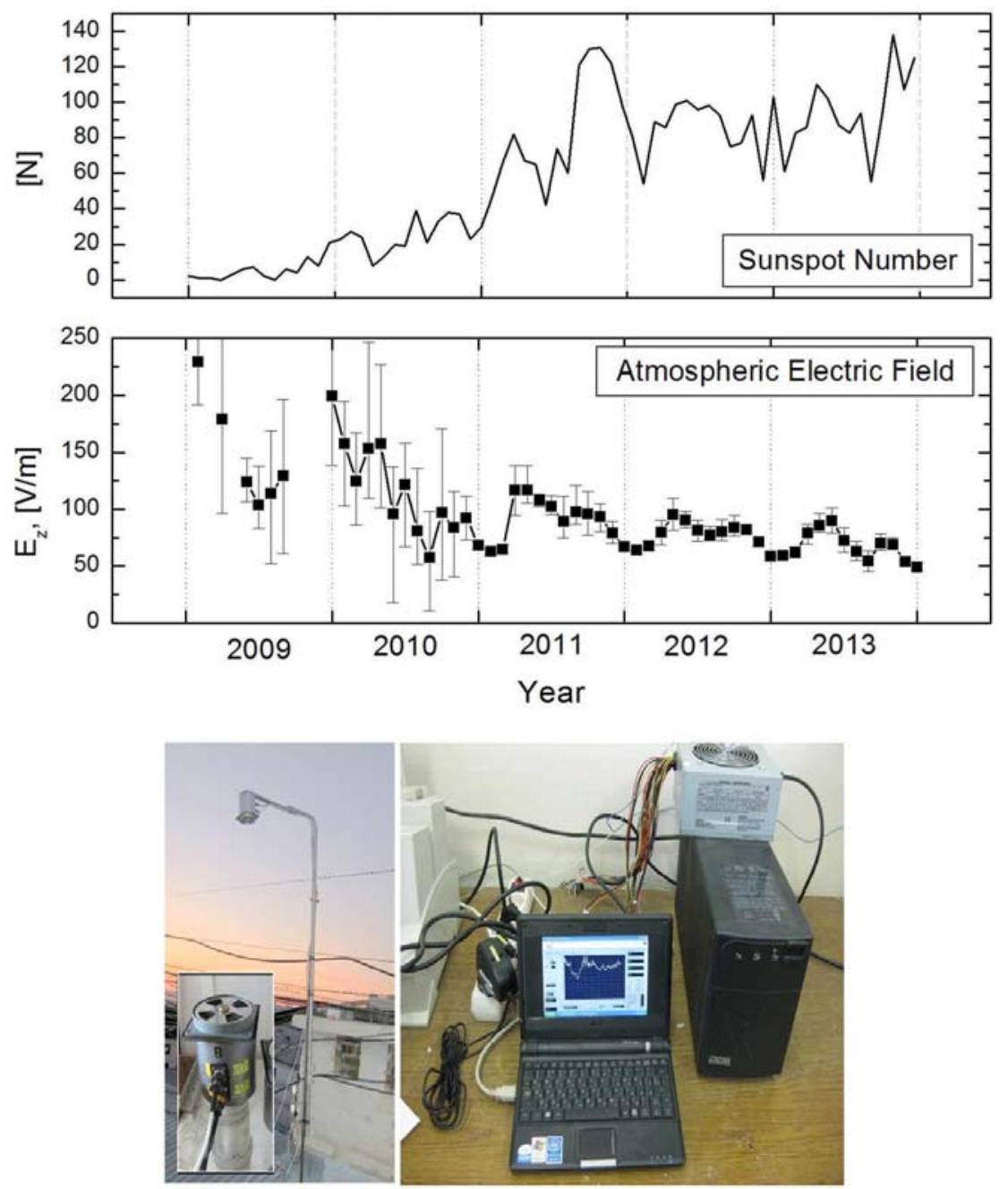

Figure 6. Variations in monthly averages of sunspot numbers (the top panel on the left side) and the atmospheric electric field strength at Yakutsk under fair-weather conditions (the bottom panel on the left side); instrumentation for registration of the atmospheric electric field (the right panel) 
toward a decrease in the amplitude of monthly averages of field strength is assumed to be a change of solar activity, which took place during the growth phase over the 2009-2013 period [Toropov et al., 2016].

\section{Cosmic noise absorption observations}

A riometer provides information about solar ultraviolet and X-rays, solar protons with energies of tens to hundreds of $\mathrm{MeV}$, as well as about precipitation of electrons with energies of tens to hundreds of $\mathrm{keV}$ and protons with $\mathrm{MeV}$ energies from Earth's magnetosphere into the atmosphere. Therefore, the riometer can be adopted to monitor electromagnetic radiation and fluxes of energetic protons from the Sun, which is essential for the study of processes occurring on the Sun and Earth. Then, subsequent analysis of electromagnetic activity of the Sun is performed to build the medium-term (13 days) forecast of upcoming geophysical disturbances. The study of precipitation of charged particles from Earth's magnetosphere allows us to solve scientific problems associated with solar wind energy transport in near-Earth space as well as with processes occurring in the magnetosphere.

The principle of riometer operation is based on the comparison of cosmic radio noise at the frequency of $32 \mathrm{MHz}$, received by the antenna wave channel, with the emission of noise diode.

In 1983-1985, under the leadership of V.D. Sokolov, a meridional riometer chain including eight observation sites from Yakutsk to Kotelny Island was created. In 2004, under the charge of S.N. Samsonov, the meridional chain was reconstructed at five observation sites (KTN, TIX, JAJ, KYS, and MAM) equipped with modern digital data loggers with 1-s sampling rate.

Figure 7 shows riometer parts including a noise generator, data logger, and power supply in the top left panel, an antenna in the top right panel, and examples of raw data for the cosmic noise absorption in Tixie $(L \sim 6)$ and Kystatyam $(L \sim 4)$ during the moderate magnetic storm on April 5-7, 2010 in the bottom panel. Intense cosmic noise absorptions were detected during periods of increased magnetic activity [Mandricova et al., 2014].

\section{Yakutia \\ Multi-instrumental observations \\ in}

An integrated approach based on multi-instrumental observations in Yakutia adopted to study various aspects of space weather effects allows us to solve a wide range of problems and to obtain scientific results.

Moiseyev et al. [2015] analyzed spatial-temporal characteristics of geomagnetic pulsations during the sudden impulse on August 4, 2010, using ground-based and satellite observations. The authors employed observations of the geomagnetic field and riometer absorption at YMC, as well as VLF emission recording data. It was indicated that there were geomagnetic pulsations of two types with different spatial extensions, oscillation frequencies, and generations. It was found that geomagnetic pulsations with identical oscillation frequencies $(\sim 4.5 \mathrm{mHz})$ at different latitudes were observed, with a maximal amplitude in the dusk sector. The oscillations with close frequencies were detected in the solar wind in the IMF $B_{z}$ component. Higher-frequency $(7-10 \mathrm{mHz})$ latitude-dependent pulsations were registered on the dawn side. It was assumed that geomagnetic pulsations with frequencies of $\sim 4.5 \mathrm{mHz}$ were caused by oscillations penetrating from the interplanetary medium, and higher-frequency pulsations were Alfven resonance oscillations generated during the compression of the magnetosphere. An asymmetric oscillation amplitude distribution relative to the noon was determined by the IMF orthospiral orientation in this event.

Long-term monitoring of dynamic changes in the human cardiovascular system under the influence of specific physical parameters of space weather is conducted at Tixie and Yakutsk, using measurements of the T-wave symmetry of electrocardiogram for a volunteer group. Samsonov et al. [2016] have revealed that the volunteers reacted to each change in geomagnetic conditions. The existence of coincident peaks in electrocardiograms and geomagnetic storminess at the two observing stations proves that changes in geomagnetic conditions affect the human cardiovascular system.

Thus, the scientific results obtained by IKIFA SB RAS scientists in space weather studies, including monitoring carried out in Russia and foreign countries, can be estimated as original results up to the world standard.

\section{INTERNATIONAL COOPERATION INTERMAGNET project}

Since 2010, the Yakutsk magnetic observatory is a member of INTERMAGNET. Participation in the INTERMAGNET (http://www.intermagnet.org/) program obliges us to provide near real-time absolute magnetic field data. These data are generally used to calculate geomagnetic activity indices $\left(A E, K_{\mathrm{p}}, D s t\right)$. The geomagnetic indices and data from individual observatories are employed to monitor geomagnetic conditions, and also as inputs to models of processes, which may have a predictive element. For example, solar and magnetic activity indices are input parameters for atmospheric density models used to compute drag forces affecting low-Earth-orbit satellites. Such models are often employed as planning tools using predicted values of the appropriate indices as inputs [Thomson et al., 2001].

\section{MAGDAS project}

The development of modern methods and tools for complex diagnostics of dynamic processes in the ionosphere-magnetosphere system based on data from ground-based observations allows us to carry out comprehensive studies of mechanisms of transfer of energy, momentum, and particles in Earth's magnetosphere and ionosphere, which determine the dynamics and state of near-Earth plasma. In particular, the study of causes and patterns of geomagnetic disturbances, which is one of the main fundamental problems of space exploration, can be successfully solved by using the global chain of magnetic stations in the northeastern region of Russia under the international projects « $210^{\circ}$ Magnetic Meridian» 

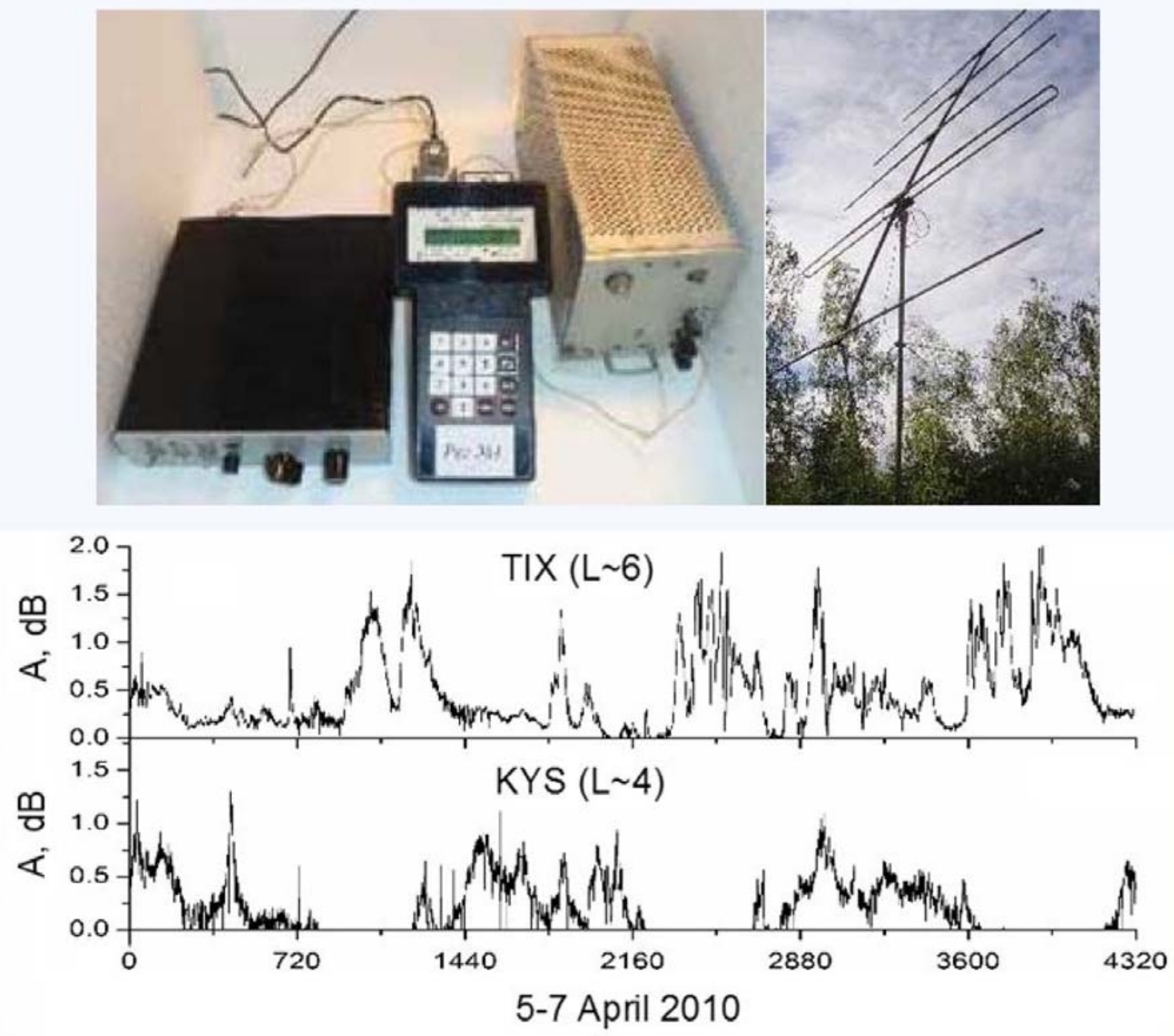

Figure 7. Riometer parts, antenna (top panel), and examples of raw data on cosmic noise absorption at Tixie $(L \sim 6)$ and Kystatyam (L 4) on April 5-7, 2010 (bottom panel)

(1991-1995), CPMN (1996-2004), and MAGDAS (2005-present), supervised by ICSWSE (former SERC) [Yumoto et al., 2006; Baishev et al., 2013]. At present, six MAGDAS-9 fluxgate magnetometers in Yakutia are operated as a high-latitude part of the global network of magnetic stations. Magnetometer network data can be used together with simultaneous satellite measurements aboard ETS-8 and QZS for space weather diagnostics.

\section{Participation in Global Ionospheric Radio Observatory (GIRO)}

Global Ionospheric Radio Observatory (GIRO, http://giro.uml.edu/) provides accurate data on electron density in Earth's ionosphere at $>60$ locations worldwide. GIRO sites are equipped with digisonde instruments that use a high-frequency remote sounding technique to probe the bottomside ionosphere from $80 \mathrm{~km}$ up to the peak of ionospheric plasma density. GIRO data are open for public access via DIDBase and DriftBase web portals, and custom software tools for the digisonde data analysis, SAO Explorer and Drift Explorer. Digisondes DPS-4 in Yakutsk (YA462) and Zhigansk (ZH466) provide a real-time ionograms for Lowell Digital Ionogram DataBase (DIDBase).
This work was partially supported by the program "JSPS Core-to-Core Program, B. Asia-Africa Science Platforms" and by the Russian Foundation for Basic Research (grants 15-45-05090 (MAV), 15-45-05005 (KVI), 15-45-05066 (SAE), 15-45-05108 (BDG, SSN), 15-45-05135 (TAA)).

\section{REFERENCES}

Baishev D.G., Barkova E.S., Yumoto K. Optical observations of large-scale undulations in the 23rd cycle of solar activity. Geomagnetism and Aeronomy. 2012, vol. 52, no. 2, pp. 197-203. DOI: 10.1134/S0016793212020028.

Baishev D.G., Barkova E.S., Yumoto K. On the relation between solar wind and evening side undulations during low planetary magnetic activity $\left(K_{\mathrm{p}}<3\right)$. Proc. 10th Intern. Conf. "Problems of Geocosmos". St. Petersburg, October 6-10, 2014. SPb. Publ., 2014, pp. 227-232.

Baishev D.G., Moiseyev A.V., Boroyev R.N., Makarov G.A., Poddelsky I.N., Poddelsky A.I., Shevtsov B.M., Yumoto K. MAGDAS international project: first results of geomagnetic observations in the territory of Yakutia. Nauka $i$ obrazovanie [Science and Education]. 2013, no. 1 (63), pp. 7-10. (In Russian).

Khalipov V.L., Stepanov A.E., Kotova G.A., Bondar' E.D. Position variations of the polarization jet and injection boundary of energetic ions during substorms. Geomagnetism and 
Aeronomy. 2016, vol. 56, no. 2, pp. 174-180. DOI: 10.1134/ S0016793216020080.

Korsakov A.A., Kozlov V.I., Mullayarov V.A., Karimov R.R. Adaptation of model parameters of VLF radio signals phase variations on the Novosibirsk-Yakutsk propagation path. Proc. SPIE. The International Society for Optical Engineering 20. Atmospheric Physics. 2014, 92924H. DOI: 10.1117/12.2074611.

Kozlov V.I., Mullayarov V.A., Karimov R.R. The response of thunderstorm VLF radio noise to solar activity according to observations in Yakutsk. Geomagnetism and Aeronomy. 2009, vol. 49, no. 8, pp. 1296-1298. DOI: 10.1134/ S0016793209080544.

Mamrukov A.P., Filippov L.D. Yakut meridional chain of VS and VIS ionosondes and daily observation of the main ionospheric trough. Effekty vysypanii energichnykh chastits $v$ verkhnei atmosfere [Effect of charged particle precipitation in the upper atmosphere]. Yakutsk, 1988. pp. 107-123. (In Russian).

Mandricova O.V., Solovev I.S., Baishev D.G. Wavelet analysis of magnetic data during the magnetic storm of April 5, 2010. Vestnik Kamchatskogo GTU [Bull. of Kamchatka State Technical University]. 2014, vol. 27, pp. 8-13. (In Russian).

Moiseev A.V., Makarov G.A., Neustroev N.I. Geomagnetic investigations in the north-eastern Russia. Vestnik Otdeleniya nauk o Zemle RAN [Bull. of the Department of Earth Sciences RAS]. 2011, NZ5004. (In Russian). DOI: 10.2205/ 2011NZ000106.

Moiseyev A.V., Popov V.I., Mullayarov V.A. Samsonov S.N., Du A., Yoshikawa A. Generation of different long-period geomagnetic pulsations during a sudden impulse. Cosmic Res. 2015, vol. 53, no. 4, pp. 257-266. DOI: 10.1134/ S001095251504005X.

Reinisch B.W., Haines D.M., Bibl K., et al. Ionospheric sounding support of OTH radar. Radio Sci. 1997, vol. 32, no. 4, pp. 1681-1694. DOI: 10.1029/97RS00841.

Samsonov S.N., Strekalovskaya A.A., Malysheva L.A., Petrova P.G., Zakharova F.A. Relationship of the geomagnetic disturbance to the state of the cardiovascular system at high latitudes on the growth phase of the 11-year solar activity cycle. Yakutskii meditsinskii zhurnal [Yakut Medical Journal]. 2016, no. 2 (54), pp. 52-54. (In Russian).

Shiokawa K., Yumoto K., Tanaka Y. et al. Auroral observations using automatic instruments: relations with multiple Pi2 magnetic pulsations. J. Geomagnetism and Geoelectricity. 1996, vol. 48. pp. 1407-1419.
Solovyev S.I., Alexeyev V.N., Baishev D.G., Ievenko I.B., Stepanov A.E., Khalipov V.L. Diagnosis of magnetosphericionospheric processes in the interaction of cold and hot plasma in disturbed periods: the results of complex measurements on the meridian of Yakutsk. Solnechno-zemnaya fizika [Solar-Terrestrial Phys]. 2002, no. 2 (115), pp. 193-196. (In Russian).

Stepanov A.E., Filippov L.D. Oblique-incidence ionospheric radio sounding measurements using digisondes data and model calculations. Vestnik Severo-Vostochnogo Fede-ral'nogo Universiteta imeni M.K. Ammosova [Vestnik of North-Eastern Federal University]. 2014, vol. 11, no. 3, pp. 60-66. (In Russian).

Stepanov A.E., Khalipov V.L., Kotova G.A., Zabolotskii M.S., Golikov I.A. Observations of large-scale plasma convection in the magnetosphere with respect to the geomagnetic activity level. Geomagnetism and Aeronomy. 2016, vol. 56, no. 2, pp. 181-186. DOI: 10.1134/ S0016793216010114.

Thomson A.W.P, King J.A., Clarke E., Clark T.D.G. Improved predictions of solar and geomagnetic influence on the near Earth environment. British Geol. Surv. Tech. Rep. 2001, $\mathrm{CR} / 01 / 162.72 \mathrm{p}$.

Toropov A.A, Kozlov V.I., Karimov R.R. Variations of the atmospheric electric field by observations in Yakutsk. Nauka i obrazovanie [Science and Education]. 2016, no. 2, pp. 58-65. (In Russian).

Yumoto K. and the MAGDAS Group. MAGDAS project and its application for space weather. Solar Influence on the Heliosphere and Earth's Environment: Recent Progress and Prospects. Eds. N. Gopalswamy, A. Bhattacharya. 2006, pp. 399-405.

\section{How to cite this article}

Baishev D.G., Samsonov S.N., Moiseev A.V., Boroyev R.N., Stepanov A.E., Kozlov V.I., Korsakov A.A., Toropov A.A., Yoshikawa A., Yumoto K. Monitoring and investigating space weather effects with meridional chain of instruments in Yakutia: a brief overview. Solar-Terr. Phys. 2017. Vol. 3. Iss. 2. P. 25-33. 